\title{
Conformación del territorio rural: campesinos y su persistencia. Un caso de la frontera sur de México
}

FORMATION OF RURAL TERRITORY: PEASANTS AND THEIR PERSISTENCE. A CASE FROM THE SOUTHERN BORDER OF MEXICO

CONFORMAÇÃO DO TERRITÓRIO RURAL: CAMPONESES E SUA

PERSISTÊNCIA. UM CASO DA FRONTEIRA SUL DO MÉXICO

\section{Nora Patricia Peraza Leal ${ }^{1}$ \\ David Velázquez Torres ${ }^{2}$}

Para citar este artículo: Peraza Leal, N. P., \& Velazquez Torres, D. (2020). (2020). Conformación del territorio rural: campesinos y su persistencia. Un caso de la frontera sur de México. Perspectiva Geográfica, 25(1), 56-76 https://doi.org/10.19053/01233769.9259.
Recepción:

11 de abril de 2019

Evaluación:

16 de marzo de 2020

Aprobación:

28 de abril de 2020

\section{Resumen}

Esta contribución tiene como objetivo introducir al lector, desde una perspectiva histórica, en el proceso de conformación del territorio rural de la ribera del río Hondo, localizada en la frontera sur de México, en los años setenta. De igual forma, se analiza la relación directa de la tenencia de la tierra con las dinámicas socioterritoriales manifestadas por el campesinado mexicano. Esto se analiza desde la teoría de la economía campesina de Marx y se contrasta con la teoría de las sociedades precapitalistas de Chayanov, en un ámbito simbiótico con la construcción del 
territorio, por medio de una metodología de diseño documental, construida con la consulta de referencias históricas en un proceso sistemático, que permitió un análisis profundo sobre diferentes categorías como la territorialidad en el campesinado o la persistencia campesina dentro del capitalismo, lo que llevó a replantearse: ¿el capitalismo promueve una desaparición o contribuye a una persistencia?

Palabras clave: territorio rural, economía campesina, campesinado, tenencia de la tierra, espacio rural, territorialidades.

\section{Abstract}

This paper aims to introduce the reader to a historical perspective on the formation process of the rural territory along the Hondo River bank, in the southern border of Mexico, during the seventies. It also discusses the direct relationship between land tenure and the socio-territorial dynamics of the Mexican peasantry. For this, Marx's theory of peasant economy and Chayanov's theory of pre-capitalist societies are used to explain the symbiosis in territorybuilding. The method employed is desk research based on historical references, which allows analyzing different categories systematically, such as territoriality in the peasantry and peasant persistence within capitalism. This results in the question: Does capitalism promote the disappearance of peasants or contribute to their persistence?

Keywords: Rural territory, peasant economy, peasantry, land tenure, rural space, territorialities.

\section{Resumo}

Esta contribuição visa introduzir o leitor, a partir de uma perspectiva histórica, no processo de conformação do território rural das margens do rio Hondo, localizada na fronteira sul do México, na década dos anos 70's. Do mesmo, analisa-se a relação direta da posse da terra com as dinâmicas socio-territoriais manifestadas pelos camponeses mexicanos. Isso é analisado a partir da teoria da economia camponesa de Marx e contrasta-se com a teoria das sociedades pré-capitalistas de Chayanov, em um ambiente simbiótico com a construção do território, por meio de uma metodologia de design documental, construída com a consulta de referências históricas em um processo sistemático, que permitiu uma análise aprofundada sobre diferentes categorias, como a territorialidade no campesinato ou a persistência camponesa dentro do capitalismo, o que levou a repensar: o capitalismo promove um desaparecimento ou contribui para a persistência?

Palavras-chave: território rural, economia camponesa, campesinato, posse da terra, espaço rural, territorialidades. 


\section{Introducción}

Los espacios rurales en México llevan a reflexionar sobre el uso social y económico que se le da a la tierra (Segrelles, 2010), enfatizando en las transformaciones territoriales, es decir, la geografía que le da el carácter espacial a los estudios del campo (Ávila, 2015). De igual forma, la cohesión y la organización del campesinado manifiestan fenómenos en lo rural que generan debates sobre las mutaciones del campo, por ende, los enfoques de lo rural se encuentran en constante transformación y relación con las dinámicas económico-productivas, las cuales rigen el uso y los cambios en los espacios rurales.

Para el presente estudio, se enfatiza en la importancia que toma el enfoque territorial en la conformación de la frontera sur de México, y cómo el actor principal del campo construye territorialidades. Se menciona la fortaleza del campesinado mexicano, el cual, a pesar de las dificultades que padece para competir económicamente con una agricultura capitalista, persiste y se reproduce (Bartra, 1975). Lo anterior se analiza desde dos perspectivas de la economía campesina: la línea chayanoviana y la línea marxista. Así, se contrastan dos enfoques que le dan sentido ecléctico a la discusión.

Adentrándonos en la conformación histórica del territorio rural de la ribera del río Hondo, se analizan tres periodos comprendidos entre los años treinta a los setenta. Este periodo es establecido para la comprensión de la reconfiguración territorial a través del análisis de las estructuras que ya se encontraban establecidas en la frontera sur. Por otro lado, a pesar de que la vocación del suelo en Quintana Roo no es de gran potencialidad para el desarrollo de actividades primarias a gran escala, la zona de estudio es la que cuenta con los mejores suelos para el desarrollo de actividades agropecuarias. De igual forma, la entidad cuenta con una frontera natural (el río Hondo) que le separa de los países de Belice y Guatemala (Herrera Sansores, 2011).

La tenencia de la tierra, para el presente trabajo, se toma como eje central para comprender la conformación y la transformación socioterritorial en la frontera sur, así como su influencia en la permanencia y reproducción campesina. Por lo tanto, es indispensable explicar las tres formas jurídicas de tenencia de la tierra en México, las cuales son: la propiedad nacional, la propiedad privada y la propiedad social; esta última incluye el régimen ejidal, en el cual se va a profundizar a continuación.

Los ejidos son tierras sujetas a un régimen de propiedad social que constitucionalmente reconoce tal personalidad y protege de manera especial su patrimonio. Se dividen en asentamiento humano, uso común, parceladas y propiedad privada (Warman Gryj, 1994). Se enfatiza en el análisis de la política de reparto de tierras, ya que los campesinos que repoblaron los ejidos de la ribera del río Hondo, en su mayoría, se encontraban atados a un régimen feudal en el cual fueron desposeídos de sus tierras, por lo que la dotación de espacios ejidales permitió la construcción y el apego a un territorio. Por consiguiente, la discusión cae en la necesidad de ser abordada desde un análisis teórico y conceptual que permita dar respuesta a las situaciones que se vivieron y se viven en el territorio rural del sur de México.

A pesar de que hasta la actualidad el Gobierno mexicano no le ha dado prioridad a la problemática del campo (Sánchez, 2014), lo rural es una prioridad en las agendas latinoamericanas y a nivel 
global (Dirven, 2019), por lo que es necesario discutir y analizar la interpretación de los fenómenos históricos para comprender las transformaciones territoriales actuales. Para el presente estudio, los ejes de análisis son los siguientes: a) el espacio y el territorio en la economía campesina, b) el campesino y su interacción en el campo y c) la conformación del territorio rural en la frontera sur de México. Para ello, se utilizó una metodología de investigación documental que recurre a insumos importantes como los libros históricos, por ejemplo: El capital de Marx y The Theory of Peasant Economy de Chayanov, entre otros, que soportan el desarrollo, el análisis y la reflexión del artículo.

\section{El espacio y el territorio rural en la economía campesina}

Las definiciones que se le han asignado al espacio rural han sido diversas y recientemente han tenido mutaciones. El espacio rural, generalmente, mas no obligatoriamente, se relaciona con las actividades del suelo, ganadería, explotación de recursos renovables y explotación forestal (Coll-Hurtado, 2005). En México, el Instituto Nacional de Estadística y Geografía (Inegi, 2010) establece metodológicamente que un espacio rural se compone de una población de 2.499 habitantes o menos y es siempre menor a una población urbana (2.49929.999 es el límite rural-urbano).

Actualmente, lo rural ha dejado de ser sinónimo de agrícola y Coll-Hurtado (2013) asevera que a lo rural se le han sumado nuevos paradigmas como el "turismo rural" y "la segunda residencia". Se enfatiza que si bien la población rural se ha beneficiado, aún en estos espacios sigue existiendo pobreza, exclusión y marginación, lo cual se ha in- crementado en las últimas dos décadas debido a la fijación de precios internacionales y la eliminación del cobro de aranceles a los productos agropecuarios del Tratado de Libre Comercio de América del Norte (TLCAN) (Calderón Salazar, 2012). Igual de importante resulta puntualizar que los nuevos paradigmas han generado una polarización de la situación social de los territorios rurales, en particular, con los campesinos, por lo que es esencial hacer énfasis en que los habitantes de las zonas rurales han sido espectadores de las innumerables transformaciones de su territorio.

Delgado (1999) se refiere a esas transformaciones territoriales como un nuevo paradigma al que denomina "nueva ruralidad" y la define como la ocupación de los espacios rurales tradicionales por actividades modernas, urbanas o industriales. Estas actividades modifican la actividad agropecuaria haciéndola solo una y no la más sobresaliente. En contraste, Mikkelsen (2013) afirma que la ruralidad ni es vieja ni es nueva, más bien responde a la construcción social de los territorios rurales contemporáneos, y que, debido a las influencias espaciotemporales, estos se han ido moldeando y adaptando a la modernidad.

El territorio, para diversidad de geógrafos, tiene un carácter meramente político. Sin embargo, para el presente análisis, con base en la definición de Giménez (2004), el territorio se aborda como un espacio apropiado por un grupo social que asegura su reproducción y la satisfacción de sus necesidades vitales, que pueden ser materiales o simbólicas. Otro concepto importante para el análisis del territorio es el de territorialidad, que no es sinónimo del primero. Se define como un conjunto de herramientas y prácticas que garantizan la apropiación, identidad y efectividad espacial de un territo- 
rio por un grupo social, de acuerdo con Montañez y Delgado (1998). Por su parte, Ávila (2015) asevera que el sentido de pertenencia y lealtad a un territorio emerge del nivel de territorialidad. A partir de los dos conceptos anteriores, se intenta articular la relación del campesino con la tierra y se discute desde las principales teorías que analizan lo rural, para que, por medio de ellas, se estudie la realidad social.

Las teorías del desarrollo y la dependencia proporcionan un panorama general de las problemáticas de la pobreza de Latinoamérica. Analizan cómo, aunque sean territorios "capitalistas", el capitalismo se ha visto imposibilitado para desarrollarse de manera pura, creando así un "capitalismo dependiente" que mantiene e incrementa problemas como la pobreza y la marginación (Otero, 1978). Por otra parte, se discute la teoría marxista, la cual propone la desaparición del campesinado para una posterior proletarización, y la línea Chayanoviana propone que, a pesar de las dificultades que enfrenta el campesino en el capitalismo, este persiste y se reproduce. Lo anterior aporta fundamentos para explicar las configuraciones y transformaciones que se han presentado en los territorios rurales de México.

En el siguiente esquema (Figura 1) se articulan las diferentes teorías que analizan lo rural con los conceptos geográficos de territorio y territorialidad y su relación con el campesino para poder interpretar la realidad social en el campo, así como su conformación y su configuración.

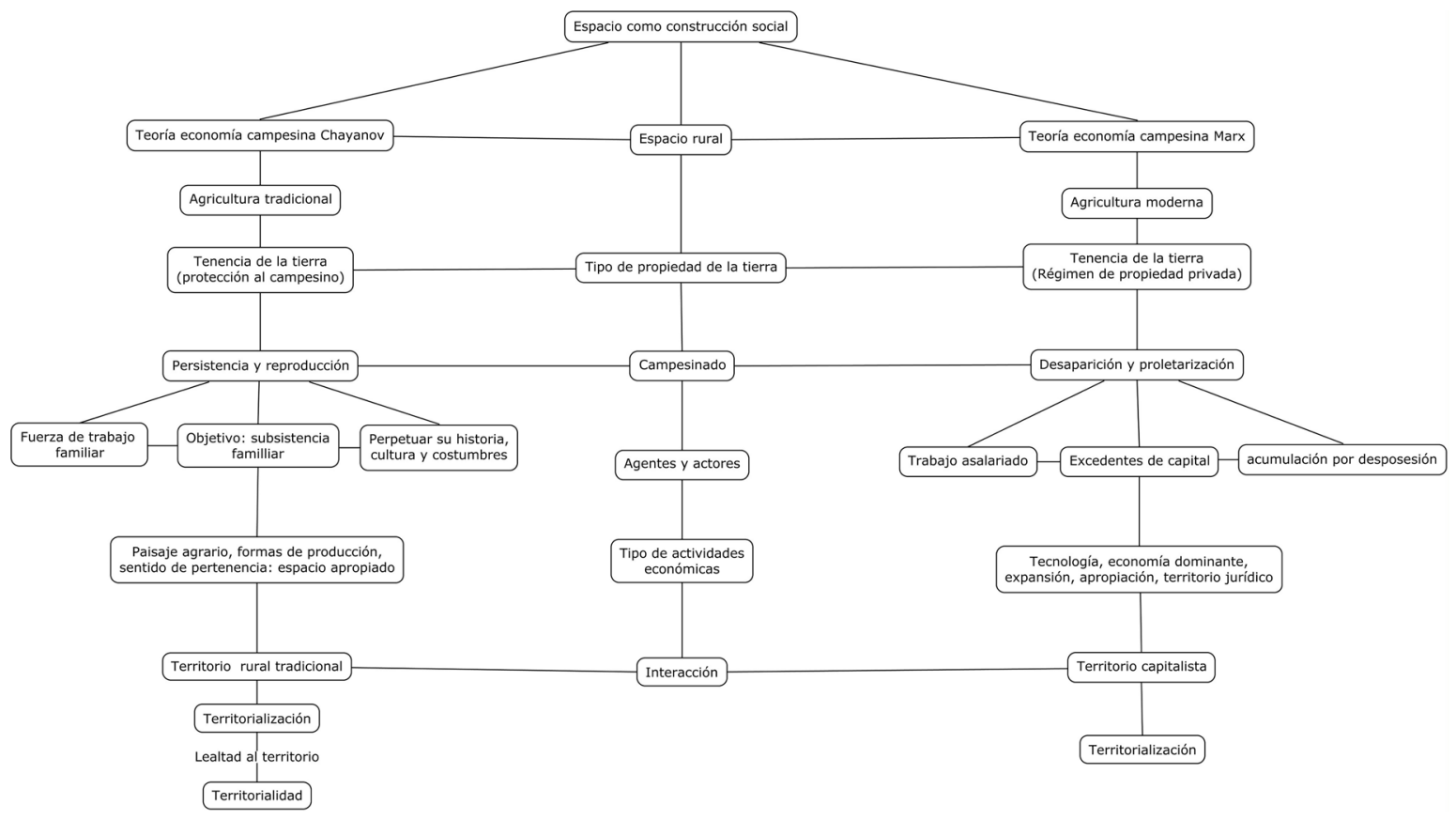

Figura 1. Esquema de análisis y articulación teórico-conceptual 
En la Figura 1 se expone de forma general la vinculación entre la geografía y la economía. Ambas ciencias aportan teorías y conceptos que se utilizan y articulan en la interpretación de la conformación y la configuración de territorios rurales. Es destacable la relación espacio-tenencia de la tierra, así como su relación con el campesino, lo cual es un factor clave que permite una persistencia y reproducción o, contrariamente, una desaparición. De igual forma se visualizan diferentes factores, los cuales, al interactuar en el espacio, producen dinámicas sociales y, como resultado, emerge un tipo de territorio.

El territorio rural y sus actores sociales (campesinos), dentro del modo de producción capitalista, profundizan las desigualdades sociales desarrolladas en el territorio, en donde llegan a ser invisibles dentro de la estructura económica y espacial, por lo que estudiar las desigualdades interdisciplinariamente es una tarea de suma importancia para la geografía. Es importante enfatizar en la protección de los territorios rurales, en particular en la defensa de las tierras, es decir, una justicia agraria que no se visualiza del todo desde la reforma al artículo 27 constitucional del 6 de enero de 1992 (artículo que rige las formas y el tipo de propiedad de las tierras) que, según Herrera (2009), “eliminó el Estado benefactor para dar libre acceso a un Estado neoliberal" (p. 13).

Por otra parte, Schejtman (1980) y Diez y Kostlin (2009) coinciden en que la teoría de Chayanov y la teoría marxista son los enfoques teóricos más utilizados para analizar los procesos territoriales en el campo. Ambos autores simpatizan más con la teoría marxista y aseveran que la inserción de capital tecnológico en el campo es de suma importancia para llegar al desarrollo, pero surge así un cuestio- namiento: ¿en Latinoamérica la inserción de la tecnología en el campo ha beneficiado o empobrecido más al campesino?

De acuerdo con la Comisión Económica para América Latina y el Caribe (Cepal, 1981), a pesar de que en algunos lugares de Latinoamérica se ha insertado tecnología agraria, en el campo aún persisten condiciones de desigualdad y exclusión en el campesinado. Bartra (1975) analiza, en un interesante dualismo, las condiciones de desigualdad como un proceso de "exclusión-reproducción" del campesinado, donde históricamente, en las luchas campesinas, se han exigido mejores condiciones de vida y se ha dado una lucha constante por la tierra que les permita situarse como productores (Pierre, 1990). Retomando el dualismo, las exigencias dicen mucho sobre las condiciones de vida de los campesinos de México que, a pesar de la exclusión, continúan siendo funcionales en el capitalismo, siguen originando territorialidades y persisten.

Es importante articular la persistencia con la baja demanda de precios de productos agrícolas del campesinado. Schejtman (1980) asevera que lo anterior forma parte del equilibrio (trabajo-consumo), lo que permite que acepten remuneraciones muy bajas por su trabajo para que de esta forma puedan persistir. Esta aserción puede explicar la persistencia campesina, ya que, a pesar de los embates del capitalismo, el equilibrio del campesinado permite que subsistan y se reproduzcan. Sin embargo, ¿esta aseveración puede explicar la permanencia campesina en Latinoamérica? Se considera que, además del trabajo-consumo que menciona Schejtman (1980), los campesinos en México han producido un fuerte arraigo al territorio y el apego se ha generado porque históricamente fueron desposeídos 
de sus tierras por el régimen feudal. Entonces, más que una subsistencia económica, la persistencia ante el capitalismo es una cuestión cultural y de resistencia.

Actualmente el capitalismo se sigue expandiendo en el territorio campesino en Latinoamérica (Díaz, 1979), y si esta tendencia sigue la expansión se realizará sobre la ruina cada vez más pronunciada del campesinado, que convertirá al territorio campesino y su fuerza de trabajo en mercancías. Además, la permanencia y reproducción en Latinoamérica se deben a la imposibilidad del capitalismo dependiente de proletarizar al campesino, ya que en América Latina siempre se han tomado medidas para la protección del principal medio de producción del campesino: la tierra; por ejemplo, en México esto sucede con los ejidos. Sin embargo, el capitalismo se apropia de los excedentes del campesinado y esta situación, según Díaz (1979), es una regla en Latinoamérica, la cual sigue reproduciendo campesinos sumergidos en la pobreza. De acuerdo con Heyning (1982), se sabe que los campesinos se encuentran en territorios subdesarrollados y dependientes. Entonces surge la cuestión: ¿los campesinos de Latinoamérica pueden representar la "forma clásica" de campesino que Marx analiza?

En contraste con Marx, Chayanov (1966) enfatiza que el visualizar al campesinado como una empresa capitalista es un error, puesto que la empresa capitalista utiliza trabajadores asalariados y, según Chayanov, el campesinado no utiliza estos factores capitalistas: por el contrario, los campesinos dependen del trabajo de su propia familia.
Por lo anterior, Chayanov (1966) propuso en su teoría tomar la unidad familiar campesina como un núcleo. Chayanov admitió que los economistas clásicos se resistían a su teoría, ya que se aferraban a la interpretación de un solo sistema: una economía universal sobre la que llevaban estudiando décadas. Sin embargo, Chayanov enfatizó que ese arraigo de doctrina estaba destinado a fracasar frente a la interpretación de la economía campesina.

Por el contrario, Figueroa (2005), en concordancia con Marx (2000), contradice la teoría de Chayanov y asevera que "el campesinado que produce sus propios medios de producción se transformará gradualmente en un pequeño capitalista que también explota el trabajo de otros [...] y se transformará en trabajador asalariado" (Figueroa, 2005, p. 36), $\mathrm{y}$, con esta tendencia, la teoría marxista sería la antítesis de la teoría de Chayanov (Kautsky, 2015).

Por otro lado, en ambas teorías hay poca profundización en la relación campesino-tenencia de la tierra, ya que se enfocan solamente en elementos económicos. Esta relación es un factor determinante en Latinoamérica debido al proceso histórico de colonización y la presencia de una aristocracia feudal, lo cual deriva en la desaparición o la permanencia. Estos procesos socioterritoriales están fuertemente relacionados con cuestiones de identidad y territorialidad que, si bien no se consideran en las teorías de Marx y Chayanov, son componentes que se intenta articular en este trabajo para situarlos en contextos dinámicos y diversos, en donde se considera que la tenencia de la tierra es la piedra angular de los procesos territoriales complejos. De ahí surge la siguiente cuestión. 
2.1. ¿Los procesos socioterritoriales de persistencia campesina son manifestados a partir del apego a su territorio?

La estructura agraria mexicana, articulada a la expansión del capitalismo en el campo, está creando un proceso de "articulación-destrucción”, asevera Otero (1978), donde el campesinado se encuentra relacionado con la industria capitalista al grado de perder su territorio y proletarizarse. Es importante puntualizar que las actividades del campo en México son diversas. Si bien es cierto que existen espacios rurales que se han convertido en agroindustrias capitalistas, de igual forma existen zonas donde los campesinos deciden no privatizar ni vender sus tierras y continúan con sus costumbres y técnicas generacionales. Por lo anterior no concordamos con el proceso de "articulación-destrucción" que señala Otero (1978), y se propone una modificación: verlo como un proceso de "vinculación-adaptación" de las dinámicas socioterritoriales al sistema capitalista, es decir, una relación sin implicaciones de pérdida de identidad o territorio.

Cabe destacar que a pesar de que la lógica de reproducción está ligada a la teoría chayanoviana, autores como Bartra (1975) y Rubio (2008) hacen énfasis en que la agricultura campesina se encuentra articulada al sistema global y no se puede estudiar sin sus singularidades y sin el uso de conceptos económicos como salario, renta de la tierra y ganancias, por mencionar algunos. En concordancia con Bartra (1975), el campesinado mexicano es inseparable del capitalismo; aunque en Latinoamérica se aplique un capitalismo dependiente, este sigue articulado al mercado global. Por ello optamos por relacionar ambas teorías y sus factores, adaptándolos a la dinámica económico-productiva del campesino y su relación con la tierra.

Figueroa (2005) asevera que es de suma importancia tener claro que la unidad campesina no es capitalista para así poder comprender su dinámica. Esto no quiere decir que se encuentre separada del modo de producción dominante, ya que debe tener relación comercial. No obstante, el objetivo del campesinado latinoamericano es diferente al de la agricultura capitalista. Para entender la lógica capitalista y la lógica campesina se debe comprender la importancia que se le da a la tierra (González, 2016), ya que generalmente la industria capitalista la titula y la privatiza porque adquiere un valor monetario, pero si no llega a ser funcional, la tierra se vende. Por el contrario, el campesino mexicano decide no privatizar sus tierras, sean o no funcionales; las conserva y trabaja en agricultura de subsistencia, ganadería en pequeña escala o las conserva para heredar $y$, por ende, les proporciona identidad, permanencia y reproducción. A partir de ello se puede afirmar que, para el campesino, la tierra y los procesos que desarrolla en ella generan un apego.

Bartra (1975) analiza ambas teorías y expone que el trabajo o mano de obra del campesinado en México carece de un valor y lo identifica como un sistema económico diferente al capitalismo marxista, aunque no pueda separarse del sistema. Aún con esta relación, no ha sido absorbido ya que en México se cuenta con un "capitalismo dependiente", es decir, que no funciona en forma pura. En el mismo sentido, es importante rescatar que el campesinado mexicano intenta perpetuar su historia, su cultura y sus costumbres, lo cual influye en su reproducción. De forma similar, Kervyn (1987) hace énfasis en las condiciones locales concretas, históricas, 
geográficas, culturales y sociales, entre otras que contribuyen a generar un arraigo e impedir su reproducción en un contexto diferente. Es entonces que surge otro cuestionamiento.

\section{2. ¿El capitalismo dependiente también influye como factor para la reproducción campesina en México?}

En contraste, Bartra y Otero (1988) aseveran que en México existe un proceso de proletarización campesina y de acumulación capitalista. Entonces, ¿el futuro del campesinado en México es la desaparición? Si bien el campesinado presenta dificultades en el modelo capitalista dependiente, invita a repensar en las vías que debe utilizar para subsistir en la periferia del sistema capitalista mundial, el cual exacerba las contradicciones al interior del capitalismo en México y Latinoamérica. El capitalismo dependiente, si bien influye en la agudización de la crisis campesina, no se puede considerar como eje central para la permanencia y reproducción del campesinado en México, ya que también existen factores políticos, ambientales y culturales. Estos son factores que le dan matices al fenómeno, pero no determina el análisis ni la reflexión teórica.

De la discusión anterior surge la cuestión: ¿cuál teoría aplica para Latinoamérica? Y en lo particular, ¿qué teoría es apta para comprender la realidad del campesinado en México y, en específico, del sur sureste mexicano? Para responder lo anterior se debe comprender al campesino inserto en una economía dependiente y en crisis, con un pensamiento histórico feudal, en su relación con la tierra. Solamente de esta forma se puede avanzar en la reflexión y en una propuesta teórica basada en los postulados de Marx o Chayanov que responda, justifique y explique lo que hoy acontece en el territorio rural del sureste mexicano.

Es importante mencionar que la economía campesina latinoamericana ha sufrido diferentes mutaciones históricas derivadas de cuestiones políticas y económicas globales. Es por ello por lo que se coincide con Kervyn (1987) cuando asevera que el campesinado en América Latina es una mezcla, ya que ni es completamente de subsistencia ni por completo mercantil. Por lo anterior, los estudios rurales en México no se deberían analizar solamente desde una perspectiva teórica, ya que existen demasiados cambios y factores como la integración del mercado y las constantes reestructuraciones económicas, así como los paradigmas ambientales insertados en las políticas públicas. Estos factores generan adaptaciones y mutaciones en los territorios rurales latinoamericanos. Consecuentemente, es importante puntualizar que una sola teoría de la economía campesina para el análisis rural es insuficiente. El análisis debe ser heterogéneo, a pesar de que diversidad de autores apuesten por la teoría marxista para los estudios rurales. No se puede ignorar la adaptación y la resistencia del campesino mexicano, que se visualizan en su apego a la tierra y su articulación al sistema.

Ávila (1999) asevera que los actores sociales, y en particular los campesinos, identifican el territorio rural como el espacio donde generan su cultura, a la cual intentan arraigarse y con la que mantienen un fuerte sentido de pertenencia. Esta aseveración tiene una implicación en los territorios rurales de México, donde a pesar de la marginación y la pobreza el campesino decide seguir con sus prácticas productivas, sus costumbres, la conservación y el apego a su tierra. Este apego al territorio los 1leva a seguir desarrollando sus dinámicas, las cuales 
crean una territorialidad que ha dejado marcas en los espacios rurales de México.

\section{El campesino y su interacción en el campo}

El concepto campesino es amplio y heterogéneo, pero para contar con un contexto histórico de este concepto es necesario mencionar a Wolf (1971), quien fue pionero en realizar una tipología del campesino. En los años cincuenta, este autor catalogó al campesino como un productor rural o agrícola que es propietario de la tierra y controla el lugar que cultiva; estos cultivos son utilizados para su subsistencia y una parte es destinada para comercialización. Años más tarde, Wolf modificó su concepto para agregar el excedente de producción. De acuerdo con Tocancipá-Falla (2005), el término campesino en América Latina se refiere a una persona que se le relaciona con un sistema axiológico donde se vincula al campesinado con "gente poco estudiada". Fairstein (2013) enfatiza que el campesino latinoamericano intenta recuperar determinadas tradiciones, cultos y formas de vida que se habían olvidado y busca practicar; de esta forma, intenta dar valor a lo tradicional para conservar su esencia y reproducción. Asimismo, Fairstein (2013) enfatiza la relación del campesinado y el territorio por medio de los paisajes, la arqueología y las formas de producción de la tierra. Todas esas formas de vida del campesino van dejando marcas en el territorio y de esta forma se van produciendo territorialidades campesinas, las cuales pueden ser visibles y fortalecen su identidad construida en el tiempo y el espacio.

La territorialidad campesina contiene una arista de gran importancia: la tenencia de la tierra. Este fac-

Vol. 25 N. 1

enero - junio de 2020

pp. $56-76$ tor ha sido causa de una lucha constante del campesinado y ha desencadenado movimientos campesinos. Por ejemplo, en México, el movimiento zapatista que se dio entre 1910 y 1920, según Díaz (1979). De la misma forma, Escalante (2001) realiza un recorrido histórico por las modificaciones al artículo 27 de la Constitución mexicana en donde menciona los decretos sobre la tenencia de la tierra desde 1917 hasta 1993. La última fecha fue cuando se estableció la certificación de las parcelas ejidales y la privatización de estas. En México, las comunidades, los ejidos y la propiedad privada constituyen la modalidad de propiedad de la tierra exclusiva en el país (Morett \& Cosío, 2017).

Discutir sobre procesos territoriales en lo rural es mencionar a todos los actores y los objetos presentes en el espacio. Sin embargo, hoy en día en América Latina aún se realizan estudios de desarrollo rural fuera del enfoque del territorio en los cuales se hace un intento por mejorar la situación de la sociedad rural, pero el enfoque es más sectorial, según Massiris (2015), por lo que solo se toma en cuenta el desarrollo particular de un sector. La importancia del territorio y su conceptualización van más allá de la palabra y su significado, más bien se trata de articular globalmente actores públicos y privados, gobierno y sociedad y todo aquel que se encuentre vinculado al territorio rural que se requiera gestionar.

Por otra parte, la conformación y el modelado territorial en la frontera sur de México se centran en Quintana Roo, durante tres etapas históricas relacionadas con sus periodos de poblamiento. El primer periodo comprende de los años treinta a los sesenta, con el auge del chicle ${ }^{3}$ y el reparto agrario

El chicle es un producto resultante de la deshidratación de la resina del árbol de chicozapote, con la cual se preparaban barras de color blanco envueltas en hojas de maíz para su 
forestal para su explotación; el segundo periodo, que se analiza a profundidad para fines de esta investigación, se remonta a los años setenta, con la colonización dirigida; el análisis de los procesos territoriales finaliza con la formación de Quintana Roo como estado.

endurecimiento. En Quintana Roo la explotación de este árbol era desarrollada por mayas y mestizos a través de técnicas ancestrales, y comenzó aproximadamente en 1880 Actualmente su proceso es a escala industrial para consu mo nacional y también para exportación (Pérez, 2014).

\section{Conformación del territorio}

\section{rural en la frontera sur de}

\section{México}

El territorio rural en la ribera del río Hondo (frontera sur de México) se localiza en las coordenadas latitud norte: $18^{\circ} 28^{\prime} 55^{\prime \prime}$ y longitud oeste: $88^{\circ} 52^{\prime}$ 50 " (Figura 2).

\section{Ubicación de la Ribera del Río Hondo}

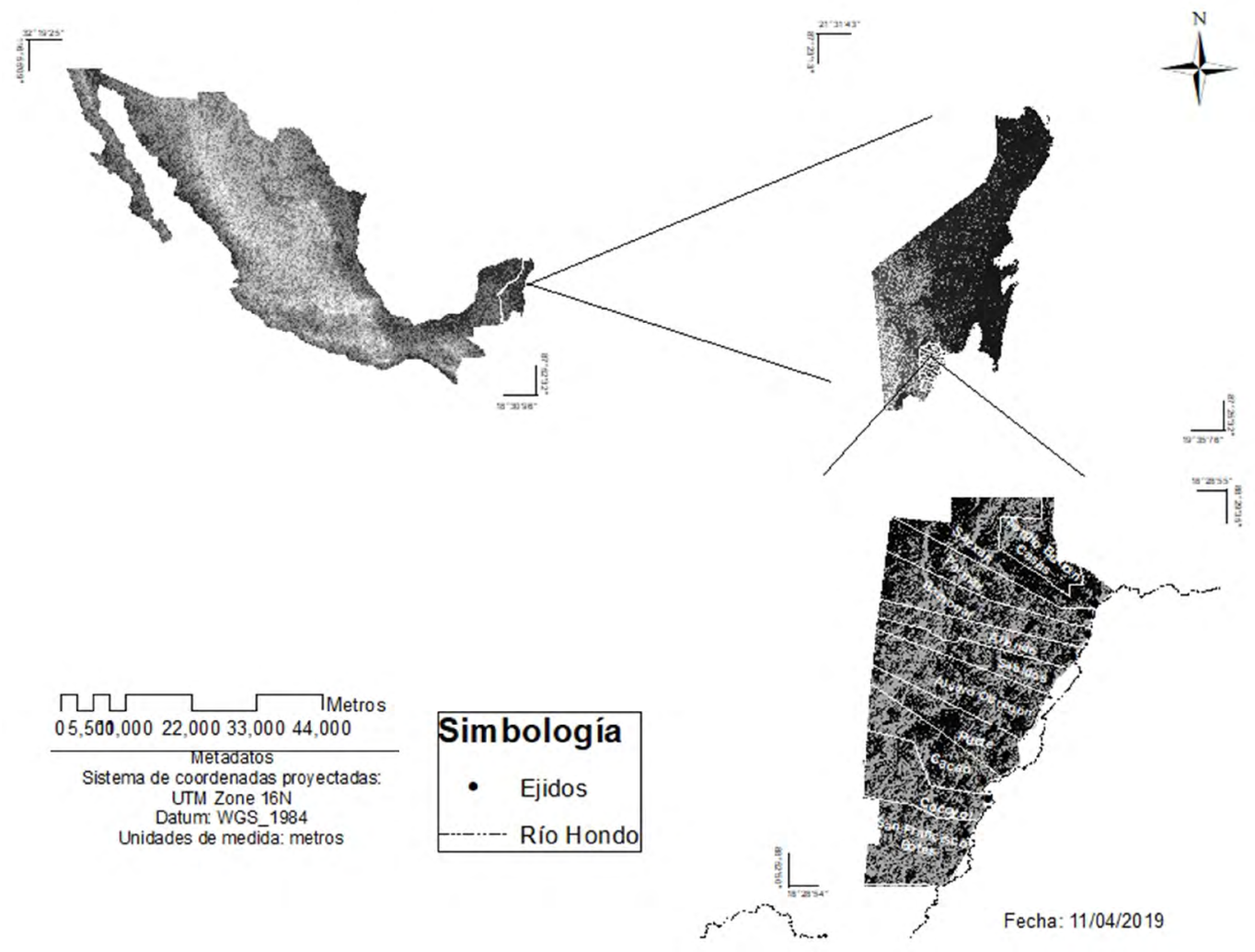

Figura 2. Ubicación de la ribera del río Hondo, frontera sur de México

Fuente: elaboración propia con datos de Inegi (2010).

Para comprender la conformación de la ribera del río Hondo, se tienen que explicar los procesos territoriales desarrollados a partir del año 1892 , cuando comienzan las disputas territoriales entre Campeche y Yucatán (Quintana Roo, para 1821, aún pertenecía a Yucatán). De acuerdo con Higue- 
ra (1997), este fue uno de los factores que desencadenó la Guerra de Castas (1847-1901), en la cual los indígenas mayas se asentaron en gran parte de Quintana Roo, desde Felipe Carrillo Puerto hasta la ribera del río Hondo, donde se arraigaron y apropiaron del espacio y lo convirtieron en su territorio, al cual llamaron Chan Santa Cruz, "Territorio Maya" (Figura 3) (Caso \& Aliphat, 2016).

\section{Chan Santa Cruz "Territorio Maya"}

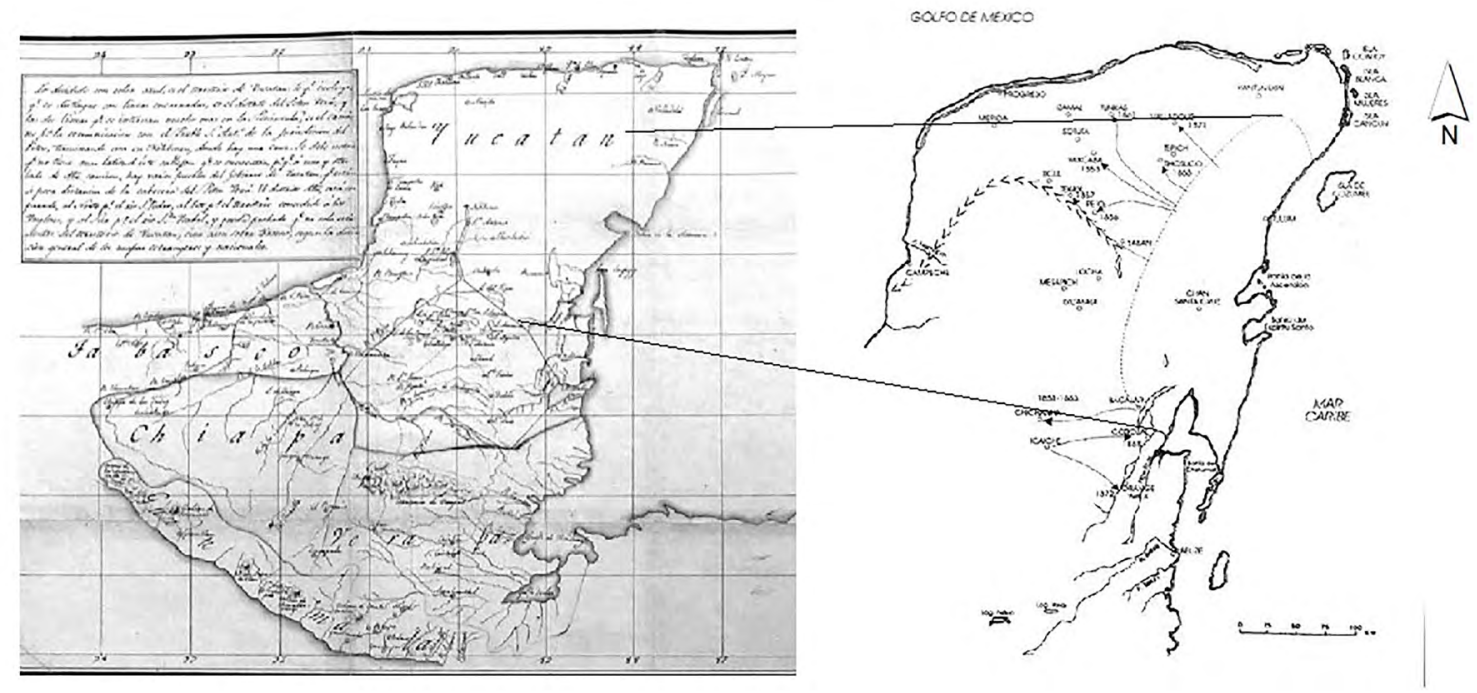

Figura 3. Chan Santa Cruz, "Territorio Maya" durante la Guerra de Castas. Izquierda: Domingo Fajardo, "copia realizada por Domingo Lascano", 1827, Archivo Histórico Genaro Estrada (AHGE); derecha: mapa de la Guerra de Castas

Fuente: izquierda: Caso y Aliphat (2016); derecha: Navarrete (2014).

A pesar de lo anterior, el Gobierno mexicano otorgó concesiones para la explotación de madera y chicle a empresas extranjeras, sometiendo a los mayas a un régimen feudal de pérdida de territorio; de acuerdo con Careaga e Higuera (2012), interpretaron como "espacios vacíos" los territorios indígenas (González Ponciano, 2006). Consecuentemente, esto detonó un desplazamiento y líneas de fuga de los indígenas, generando así una desterritorialización; por ende, se reconfiguró y reterritorializó la frontera sur por parte de empresas extranjeras y nacionales.
Es importante destacar la relación entre la tenencia de la tierra y los decretos de 1934 y 1937, ya que hicieron un énfasis en el reconocimiento de los núcleos de población y la fragmentación de los latifundios que garantizaba la dotación de tierras para satisfacer las necesidades de la población campesina (Gómez de Silva, 2016). En el decreto de 1937 se adiciona, en la fracción VII del artículo 27, el reconocimiento del derecho de los núcleos de población comunal, es decir, que el disfrute de las tierras, bosques y aguas se debía realizar en un uso común. 
En la década de los años treinta, en la ribera del río Hondo, se produjo el auge chiclero en Quintana Roo, actividad económica que identificó ese periodo, según Romero (2018). Las características de organización social fueron en forma de cooperativa para llevar a cabo la extracción de la resina de chicozapote para la elaboración del chicle. Asimismo, el reparto agrario forestal identificó la conformación de un espacio rural. La primera cooperativa se formó en el ejido de Pucté, donde incorporaron a sus dinámicas el intercambio comercial nacional y extranjero. Posteriormente, en los años cuarenta, el gobierno de Rafael Melgar, con el fin de poner un alto a la expansión capitalista de empresas extranjeras en Quintana Roo, conformó 76 sociedades cooperativas, de las cuales 48 se dedicaban a la producción del chicle dentro de una estructura de organización ejidal y se les otorgaban permisos para su explotación.

La conformación del sur fue a través del chicle. Esa actividad fue la que configuró el territorio rural, lo que definió las estructuras sociales y económicas de los años treinta hasta principios de los cincuenta. La explotación del chicle generó una apropiación del espacio que compartían mayas, cooperativas y mestizos, quienes eran los actores principales en tal actividad. El chicle les permitía satisfacer sus necesidades vitales. De esta forma, se construyó, en el tiempo y en el espacio, una adherencia al ejido y una apropiación de sus bosques. Se puede interpretar, por lo anterior, que se contaba con una efectividad espacial creada por el tejido social que lo habitaba.

Para 1955, el auge del chicle tuvo un gran declive con la devastación de áreas forestales por el arribo del huracán Janet. Tal suceso es un "elemento iconográfico" en la historia de la zona sur de Quin- tana Roo, en particular de la ciudad de Chetumal (Arriaga \& Romero, 2015). Chetumal toma gran importancia en la conformación de la ribera del río Hondo, por su cercanía y porque, después de la reconstrucción de los daños causados por el huracán Janet (1955), se convirtió en un núcleo comercial y centro administrativo, de acuerdo con Arriaga y Romero (2015). De igual forma, se benefició con el régimen de zona libre para la distribución de mercancías, lo que la vinculaba con la comercialización de productos forestales y agropecuarios.

En 1960, la industria del chicle tuvo un declive producido por la aparición de gomas sintéticas. En relación con lo anterior, en la ribera del río Hondo el impacto del huracán Janet marcó su poca participación en la extracción del chicle en esos años. Después del paso del fenómeno natural, la actividad no volvió a ser la misma. Este fue el motivo por el cual los habitantes nativos decidieron desarrollar agricultura tradicional en milpas para autoconsumo y comercialización en Chetumal.

La segunda etapa, que se analiza con mayor profundidad, fue la llamada "colonización ejidal" en el periodo de los años setenta. Este periodo de poblamiento tuvo dos propósitos para el Gobierno mexicano. El primero fue que Quintana Roo se volviera estado, lo cual se llevó a cabo a través de la Secretaría de la Reforma Agraria, con una política de poblamiento y dotación de tierras para campesinos, que se encontraban en crisis, pertenecientes a otros estados. Con esta política se buscaba apoyar a los campesinos con tierras y que Quintana Roo contara con la cantidad mínima de población. El segundo propósito fue reactivar la economía del sur de Quintana Roo (González Ponciano, 2006).

A este proceso se le denominó "colonización dirigida". Fue un movimiento masivo de campesinos 
hacia los ejidos de la ribera del río Hondo, que se dio en la década de los setenta y que reconfiguró el espacio indígena y de extracción de madera y chicle para convertirlo en un espacio rural moderno, que diera seguridad alimentaria para el estado y dotara de alimento al proyecto turístico de Cancún, de acuerdo con los planes políticos del Gobierno mexicano. Estos planes estuvieron lejos de ser lo que se pensaba, ya que no tuvieron en cuenta factores edafoclimáticos, económicos y culturales que permitieran establecer una agricultura capitalista en la ribera del río Hondo (Higuera, 1997).

En el periodo de Lázaro Cárdenas existía una presión muy grande de los campesinos, por lo que se tuvo que intervenir e implementar una política de reparto de tierras. El objeto de tal reparto era liberar al campesino de la explotación latifundista y que así fuera dueño de sus propios medios de producción para poder incrementar la producción agrícola. Este proceso de dotación de tierras es clave para comprender la persistencia y la reproducción campesina en la ribera del río Hondo. De igual forma, Cárdenas también propuso el ejido colectivo, ya que su lógica era que así evitaría el abandono de tierras y los campesinos tendrían más facilidad para capitalizarse y además aumentar la producción nacional (Higuera, 1997).

La colonización dirigida en la ribera del río Hondo es uno de los instrumentos para consolidar el ejido colectivo, lo cual interpretaremos como uno de los principales factores de la estructura territorial de la frontera sur, donde se dotó de grandes extensiones de tierra, las cuales, inicialmente, se utilizaban para la explotación de madera y la industria del chicle. Sin embargo, en la década de los setenta la explotación forestal tuvo un gran declive debido al saqueo, a la no reforestación y a los incendios, por lo que se propuso la agricultura como el sustituto de la dinámica forestal (Arriaga \& Romero, 2015).

La conformación del territorio campesino en la ribera del río Hondo, de acuerdo con Fort (1979), tuvo dos factores determinantes: el primero, la estructura capitalista en sus diferentes etapas, y el segundo, las transformaciones de la tenencia de la tierra. La tenencia de la tierra es el factor que interviene directamente en la producción campesina. En el periodo de 1915 a 1970, se realizó el reparto agrario (artículo 27 constitucional). De acuerdo con Escalante (2001), en 1974 se otorgaron hectáreas para trabajar la agricultura en la ribera del río Hondo, ya que la Reforma Agraria daba por entendido que los nuevos pueblos colonizados por campesinos tenían capacidad para capitalizar la producción agrícola.

Una característica destacable de la colonización en la frontera sur de Quintana Roo es que se dio una reterritorialización forzada por un grupo de campesinos de diferentes partes de la república, con diferentes culturas y costumbres, habituados a un clima y a condiciones físicas muy distintas, en donde diferentes ejidos contaron con un importante número de trabajadores (mano de obra) que representaba la mayor parte de la fuerza de trabajo con respecto al total de los nuevos centros de población ejidal. Para el Estado era positivo que se contara con mano de obra para asegurar la producción primaria, ya que de esta forma se lograba facilitar el trámite de inversiones y sistematizar el trabajo agrícola para impulsar el desarrollo modernista y el crecimiento de los ejidos. Entonces, se puede interpretar que la configuración de los ejidos de la ribera del río Hondo tuvo un comienzo capitalista impulsado por el Gobierno, que permaneció de esta forma al menos durante los tres 
primeros años en los que se dio la reorganización campesina.

El Gobierno, tanto federal como estatal, hizo un gran esfuerzo por implementar en los ejidos colectivos del Estado, en particular en la ribera del río Hondo, una agricultura de tipo capitalista y mecanizada. A pesar del esfuerzo por conseguir los créditos para la capitalización por medio del Banco de Crédito Rural Peninsular, con base en la Reforma Agraria (que solo otorgaba créditos de tipo colectivo), esto no permitió la recuperación monetaria, por lo que limitó y endeudó a los campesinos colonos con el banco y puso en riesgo su futuro, y el Gobierno mexicano tuvo que aceptar que la colonización en la ribera del río Hondo no iba a poder ser una agricultura del todo moderna y que más bien se trataría de una agricultura tradicional (Fort, 1979).

Para el año de 1976, debido a los problemas de endeudamiento y falta de capital, algunos campesinos comenzaron a implementar huertos familiares. Cada huerto medía $70 \mathrm{~m} 2$, los cuales eran exclusivamente de subsistencia, según Fort (1979). Además, gran parte de los colonos no contaban con tierras en sus lugares de origen y al dirigirse a un nuevo lugar, donde el Gobierno les imponía un tipo de agricultura mecanizada (capitalista) a la cual no estaban adaptados, esto los situó en una crisis.

Es importante analizar la tendencia del campesinado a retomar la actividad de subsistencia que realizaba en su lugar de origen, por lo que podemos aseverar que la cultura es un factor importante para determinar el tipo de economía familiar. En los años posteriores, los campesinos lograron comercializar su producción con la Compañía Nacional de Subsistencias Populares (Conasupo) y consiguieron generar mínimas ganancias para poder reinvertir. Asimismo, diversos conjuntos de campesinos defendieron la idea de "grupo" como factor principal de producción y trabajo (Fort, 1979). Este trabajo en equipo, asevera Chayanov, es un factor que aporta la lógica de una persistencia campesina.

En el caso particular de la ribera del río Hondo, se tiene que realizar una distinción entre los campesinos. Los campesinos colonos, según el estudio de Fort, tuvieron mano de obra disponible de dos tipos: el primero fue la mano de obra pagada (por préstamos o capital del ejidatario) y el segundo fue la fuerza del trabajo del propio campesino que trabajaba su parcela y que, generalmente, ocupaba la producción para comercializar en mercados cercanos.

En el año de 1973 se implementó el proyecto arrocero, el cual se comercializaba en Escárcega, Campeche. Tuvo una vigencia de tres años, pero el proyecto fue insostenible para el campesino debido a que los precios del arroz en el mercado se mantenían y los insumos para su producción aumentaban. Posterior al proyecto arrocero los campesinos solicitaron un ingenio azucarero, que visualizaban como la única forma para poder subsistir en el territorio. En los años posteriores se implementó este proyecto y actualmente la agroindustria azucarera es la dinámica principal en el territorio de la ribera del río Hondo.

Posteriormente, en 1974, Quintana Roo logró contar con el mínimo de población para convertirse en estado. Este suceso produjo reconfiguraciones en todo el territorio y, en particular, en la frontera sur. Como consecuencia, se determinaron las estructuras territoriales y se produjo una recomposición territorial. Los grupos sociales dedicados a la 
producción del chicle tuvieron que reconfigurar la propiedad de los ejidos para incorporar a los campesinos dedicados a la agricultura. De igual forma, al crearse nuevos ejidos, el espacio se dividió y fue apropiado por los nuevos colonizadores, creando así un territorio rural en donde la actividad principal ya no era la producción de chicle, sino la agricultura.

\section{Conclusiones}

Es ineludible analizar la conformación del territorio de la ribera del río Hondo desde la relación campesino-tenencia de la tierra y articularla con las teorías utilizadas en el presente trabajo para justificar un acercamiento a una reflexión teórica y explicar los procesos socioterritoriales en el sur de México.

En ambas etapas de configuración y reconfiguración del territorio, las actividades del campesino mexicano nunca fueron completamente de subsistencia. Por el contrario, existió una fuerte vinculación con el capitalismo. En la primera etapa, la cooperativa dedicada a exportar chicle fungió como factor de enlace con el modo de producción dominante, y en la segunda etapa, el Gobierno desarrolló la relación de comercialización con el sistema.

Por lo anterior, se tiene claro que el capitalismo dependiente es el sistema económico de México y Latinoamérica, por lo que las teorías de Marx y Chayanov no se aplican en su totalidad para explicar la persistencia y la reproducción del campesino, así como su marginación y la crisis en el sistema económico que lo dominan. Por consiguiente, para comprender la conformación y las transformacio- nes del territorio del sur de México, se analizaron factores geográficos, socioeconómicos, culturales y las transformaciones de la tenencia de la tierra, los cuales justifican los procesos y la persistencia de su actor principal.

Históricamente, en México se ha dado una lucha y una persistencia campesina por la tenencia de la tierra, que ha sido una cuestión generacional hasta el día de hoy, visible en el nulo cambio que ha tenido la tierra hasta la actualidad a pesar de la influencia capitalista. La tierra conserva su modalidad ejidal, por lo cual se puntualiza la necesidad de tomar al campesino y su tierra como factores principales para comprender la persistencia y la reproducción campesina, así como el desarrollo de procesos socioterritoriales. Por lo tanto, se considera la relación campesino-tierra como un solo factor, que es inseparable y se encuentra articulado al sistema capitalista dependiente, el cual hace que permanezca en exclusión y que, a pesar de ello, presente una persistencia. Entonces, la relación campesino-tierra contiene un vínculo inherente al sistema dominante. Ahora bien, tomando en cuenta estas relaciones indivisibles, se realizó una simbiosis con los factores más relevantes para comprender la situación del campesino mexicano.

Los procesos socioterritoriales en la ribera del río Hondo desde la unión campesino-tierra y empresa capitalista (cooperativa-institución gubernamental) permitieron al campesino mexicano sobrevivir y capitalizarse. Por otro lado, la teoría de Chayanov puntualiza la agricultura de subsistencia como forma de vida del campesino. Sin embargo, en México es inaplicable este tipo de agricultura como único medio económico, ya que este medio terminaría por hacer desaparecer al campesinado y teóricamente es una contradicción. Si bien ambos 
procesos propuestos son una contradicción a las teorías originales, se formula una reflexión teórica en un país dependiente que impone grandes dificultades al campesino. De igual importancia es que en la frontera sur de México la agricultura de subsistencia se desarrolla, pero para fines de preservar la historia, la cultura y las costumbres y no como único medio de vida. Por ende, el análisis se efectuó a través de una dialéctica subjetiva de ambas teorías en su aplicación en la frontera sur de México para que así pueda ser replicable en Latinoamérica, lo cual se debe a que la situación del campesinado es un proceso cambiante y ascendente en el tiempo y en el espacio, ya que ver la realidad desde teorías inmóviles y en contextos económicos y culturales distintos llevaría al fracaso.

Con base en lo establecido previamente, el presente estudio analiza y compara factores de las teorías de Chayanov y de Marx para adaptar un modelo de análisis de las siguientes relaciones: la relación campesino-tierra con el capitalismo es lo que le permite "subsistir y sobrevivir" al campesino y generar su reproducción en contradicción con la desaparición y la proletarización que asevera la teoría marxista, mientras que, en la teoría de Chayanov, la agricultura de "subsistencia" le permite aplicar sus saberes generacionales, pero no le permite subsistir de ello. Al seguir este pensamiento dialéctico, se llega a la reflexión sobre cómo en la frontera sur de México el campesino permanece, se reproduce y construye su territorio.

En conclusión, se tomaron diferentes factores de ambas teorías de la economía campesina, así como las relaciones inherentes entre la tenencia de la tierra, el campesino, la territorialidad y cuestiones de cultura generacional, las cuales permitieron la configuración y la construcción del territorio, así como la manifestación de una resistencia que permite que el campesino mexicano permanezca y se reproduzca en su contexto histórico. Este proceso se sintetiza en una "vinculación-adaptación” al sistema dominante. 


\section{Referencias}

Arriaga, R. J. \& Romero, M. R. (2015). Breve historia urbana de Chetumal, Quintana Roo (1898-1912): una mirada desde el análisis de las estructuras sociales. En A. Guillermo \& I. Escamilla (coord.), Segregación urbana y espacios de exclusión: ejemplos México y América Latina (pp. 199-219). México: Miguel Ángel Porrúa.

Ávila, S. H. (1999). La dinámica actual de los territorios rurales en América Latina. Scripta Nova, Revista Electrónica de Geografía y Ciencias Sociales, 45(40). Recuperado de http://www.ub.edu/geocrit/sn-45-40.htm.

Ávila, S. H. (2015). Tendencias recientes en los estudios de geografía rural. Desarrollos teóricos y líneas de investigación en países de América Latina. Investigaciones Geográficas, 88, 75-90. doi: dx.doi.org/10.14350/rig.44603.

Bartra, R. (1975). La teoría del valor y la economía campesina: invitación a la lectura de Chayanov. Revista de Comercio Exterior Bancomext, 25(5), 518-524. Recuperado de http://revistas.bancomext.gob.mx/rce/magazines/709/5/RCE5.pdf.

Bartra, R. \& Otero, G. (1988). Crisis agraria y diferenciación social en México. Revista Mexicana de Sociología, 50(1), 13-16. Recuperado de https://www.sfu.ca/ otero/docs/Bartra-Otero-1988.pdf.

Calderón Salazar, J. A. (2012). TLCAN y la situación actual de la agricultura mexicana. En Desarrollo rural y crisis alimentaria en México (pp. 39-42). México: Senado de República LXI Legislatura, Instituto Belisario Domínguez. Recuperado de https:// archivos.juridicas.unam.mx/www/bjv/libros/7/3338/10.pdf.

Careaga, V. L. \& Higuera, B. A. (2012). Quintana Roo. Breve historia. México: Fideicomiso Historia de las Américas (Colmex).

Caso, B. L. \& Aliphat, F. M. (2016). De antiguos territorios coloniales a nuevas fronteras republicanas: la guerra de castas y los límites del suroeste de México 1821-1893. Historia Crítica, 59, 81-100. doi: dx.doi.org/10.7440/histcrit59.2016.05.

Chayanov, A. (1966). The Theory of Peasant Economy (D. Thorner, B. Kerblay \& R. Smith, eds.). Illinois, Estados Unidos: The American Economic Association (obra original publicada en 1925). Recuperado de https://growthecon.com/assets/papers/ alexander_chayanov_the_theory_of_peasant_economy.pdf.

Comisión Económica para América Latina y el Caribe (Cepal). (1982). Economía campesina y agricultura empresarial: tipología de productores del agro mexicano. Recuperado de https://repositorio.cepal.org/bitstream/handle/11362/25265/ S8100382_es.pdf?sequence=2\&isAllowed=y.

Coll-Hurtado, A. (2005). Geografía económica de México, temas selectos. México: Instituto de Geografía, Unam.

Coll-Hurtado, A. (2013). Capítulo VI. El campo y sus habitantes: los estudios de geografía rural. En V. Mendoza (coord.), Estudios de la geografía humana en México (pp. 99-112). México: Instituto de Geografía, Unam. 
Delgado, J. (1999). La nueva ruralidad en México. Investigaciones Geográficas, 39, 80-94. Recuperado de http://www.redalyc.org/articulo.oa?id=56903906.

Díaz, P. H. (1979). Teoría marxista de la economía campesina. Mexicali, México: Juan Pablos Editor.

Diez, C. \& Kostlin, L. (2009). Persistencia y cambio del campesinado. Un abordaje crítico a "La morada de la vida" desde el marxismo contemporáneo. Mundo Agrario, 10(19), 1-5. Recuperado de https://www.mundoagrario.unlp.edu.ar/article/view/ v10n19a07.

Dirven, M. (2019). Nueva definición de lo rural en América Latina y el Caribe en el marco de FAO para una reflexión colectiva para definir líneas de acción para llegar al 2030 con un ámbito rural distinto. Serie 2030 Alimentación, agricultura y desarrollo rural en América Latina y el Caribe, Documento ${ }^{\circ} 2$. Santiago de Chile: FAO. Recuperado de http://www.fao.org/3/ca5509es/ca5509es.pdf.

Escalante, R. (2001). El mercado de tierras en México. Santiago de Chile: Cepal. Recuperado de https://repositorio.cepal.org/bitstream/handle/11362/4494/ S019764_es.pdf?sequence=1\&isAllowed=y.

Fairstein, C. (2013). "Ser campesino" como el desarrollo de un nuevo tipo de trabajador rural. Análisis de los participantes de la Red de Turismo de la Provincia de Salta Argentina. Trabajo y Sociedad, 20, 296-306. Recuperado de https://ri.conicet.gov. ar/admin/bitstream/11336/3987/2/CONICET_Digital_Nro.4943_A.pdf.

Figueroa, V. (2005). América Latina: descomposición y persistencia de lo campesino. Problemas de desarrollo. Revista Latinoamericana de Economía, 36(142), 31-43. Recuperado de https://www.redalyc.org/pdf/118/11820079003.pdf.

Fort, O. (1979). La colonización ejidal en Quintana Roo. México: Instituto Nacional Indigenista.

Giménez, G. (2004). Territorio, paisaje y apego socio-territorial. En Culturas populares e indígenas (pp. 315-328). México: Conaculta, Región Cultural.

Gómez de Silva, C. J. (2016). Reforma del artículo 27 constitucional. En C. J. Gómez de Silva, El derecho agrario mexicano y la constitución de 1917 (pp. 151-168). Ciudad de México: Universidad Autónoma de México, Instituto de investigaciones jurídicas. Recuperado de https://archivos.juridicas.unam.mx/www/bjv/libros/9/4452/19. pdf.

González Ponciano, J. R. (2006). Reseña de “El vacío imaginario. Geopolítica de la ocupación territorial en el Caribe oriental mexicano" de Gabriel Aarón Macías Zapata (coord.). Estudios de Cultura Maya, 28, 178-185. Recuperado de http:// www.scielo.org.mx/pdf/ecm/v28/v28a11.pdf.

González, S. W. (2016). Estructura agraria: lógicas disímiles en la concepción del territorio. Perspectiva Geográfica, 21(1), 117-118. doi: https://doi. org/10.19053/01233769.4578.

Herrera Sansores, J. C. (2011). Hidrología subterránea. En C. Pozo, C. N. Armijo \& S. Calmé (eds.), Riqueza biológica de Quintana Roo: un análisis para su conservación 
(pp. 34-43). México: Conabio. Recuperado de https://es.slideshare.net/ RicardoPachecoRios/1-capitulo-baja.

Herrera, T. F. (2009). Apuntes sobre las instituciones y los programas de desarrollo rural en México. Del estado benefactor al estado neoliberal. Revista de Estudios Sociales, 17(33), 11-13. Recuperado de http://www.scielo.org.mx/pdf/estsoc/ v17n33/v17n33a1.pdf.

Heyning, K. (1982). Principales enfoques sobre la economía campesina. Revista Cepal, 16, 2-18. Recuperado de https://repositorio.cepal.org/bitstream/ handle/11362/22026/S8200202_es.pdf?sequence=1\&isAllowed=y.

Higuera, B. A. (1997). Quintana Roo entre tiempos: política, poblamiento y explotación forestal 1872-1925. Chetumal: Editorial Norte Sur.

Instituto Nacional de Estadística y Geografía (Inegi). (2010). Marco geoestadístico. Recuperado de www.inegi.gob.mx.

Kautsky, K. (2015). La cuestión agraria: estudio de las tendencias de la agricultura moderna y de la política agraria de la socialdemócrata. Marxists Internet Archive [edición digital]. Recuperado de https://www.marxists.org/espanol/kautsky/1899/ kautsky-la-cuestion-agraria.pdf.

Kervyn, B. (1987). La economía campesina en el Perú: teorías y políticas. Seminario Permanente de Investigación Agraria (SEPIA II), 31-39. Recuperado de http:// centroderecursos.cultura.pe/sites/default/files/rb/pdf/La_economia_campesina_ en_el\%20Peru_Teorias_y_politicas.pdf.

Lefebvre, H. (1984). The production of space. Massachusetts: Anthropos.

Marx, K. (2000). El capital. Madrid: Editorial Akal.

Massiris, P. Á. (2015). Gestión del territorio para usos agropecuarios, bases para la formulación de política pública. Bogotá: Unidad de Planificación Rural Agropecuaria (UPRA).

Mikkelsen, C. (2013). Debatiendo lo rural y la ruralidad: un aporte desde el sudeste de la provincia de Buenos Aires; el caso del partido de Tres Arroyos. Cuadernos de Geografía, 22(2), 237-241. doi: https://doi.org/10.15446/rcdg.v22n2.30993.

Montañez, G. G. \& Delgado, M. O. (1998). Espacio, territorio y región: conceptos básicos para un proyecto nacional. Cuadernos de Geografía, 7(1-2), 120-134. https://www.crossref.org/iPage?doi=10.15446\%2Frcdg.

Morett, S. \& Cosío, R. (2017). Panorama de los ejidos y comunidades agrarias en México. Agricultura, Sociedad y Desarrollo, 14(1), 126-131. Recuperado de http:// www.scielo.org.mx/pdf/asd/v14n1/1870-5472-asd-14-01-00125-en.pdf.

Navarrete, M. G. (5 de febrero de 2014). La guerra de castas. Mérida de Yucatán. Recuperado de https://www.meridadeyucatan.com/la-guerra-de-castas/.

Otero, G. (1978). Economía campesina y articulación-destrucción de modos de producción. Cathedra, Revista de la Facultad de Filosofía y Letras de la Universidad de Nuevo León, 7, 31-38. Recuperado de http://www.sfu.ca/ otero/docs/ Econom\%C3\%ADa-Campesina-Cathedra-1978.pdf. 
Pérez, R. (2014). El chicle en Quintana Roo: sus caminos y voces. Cuicuilco, 21(60), 195-222. Recuperado de http://www.scielo.org.mx/scielo.php?script=sci_ arttext\&pid=S0185-16592014000200010.

Pierre, R. (1990). El campesinado y el marxismo. Recuperado de http://www. anticapitalistas.org/IMG/pdf/El_Campesinado_y_el_marxismo.pdf.

Romero, M. R. (2018). La industria del oro blanco de la selva maya de Quintana Roo. Un análisis territorial y desde el agenciamiento. En M. J. Delgadillo, V. I. González \& C. J. Lee, Agenciamiento de desarrollo e incidencia territorial: teorías y experiencias en el sur-sureste mexicano (pp. 149-198). Ciudad de México: Universidad Nacional Autónoma de México.

Rubio, B. (2008). De la renta de la tierra a la renta de la vida: comentario a "El capital en su laberinto". Mundo Siglo XXI, 11, 99-107. Recuperado de https://repositorio. flacsoandes.edu.ec/xmlui/bitstream/handle/10469/7320/REXTN-MS11-08Rubio.pdf?sequence=1\&isAllowed=y.

Sánchez, C. J. (2014). La política agrícola en México, impactos y retos. Revista Mexicana de Agronegocios, 35, 946-956. Recuperado de https://www.redalyc.org/ pdf/141/14131676004.pdf.

Schejtman, A. (1980). Economía campesina: lógica interna, articulación y persistencia. Revista Cepal, 11, 121-140. Recuperado de https://repositorio.cepal.org/ bitstream/handle/11362/11934/011121140_es.pdf?sequence=1\&isAllowed=y.

Segrelles, S. J. (2010). Contenidos, evolución epistemológica y fuentes de la geografía rural. Recuperado de https://rua.ua.es/dspace/bitstream/10045/19093/1/ Microsoft\%20Word\%20-\%20TEMAS_1_2.pdf.

Tocancipá-Falla, J. (2005). El retorno del campesino: una revisión sobre los esencialismos y heterogeneidades en la antropología. Revista Colombiana de Antropología, 41, 7-41. Recuperado de http://www.redalyc.org/ pdf/1050/105015281001.pdf.

Warman Gryj, A. (1994). La reforma al Artículo 27 constitucional. Recuperado de http:// www.pa.gob.mx/publica/cd_estudios/Paginas/autores/warman\%20arturo\%20 la\%20reforma\%20al\%20articulo\%2027.pdf.

Wolf, E. (1971). Los campesinos (traducción de Juan-Eduardo Cirlot). Barcelona: Grafos. 